\title{
Research Progress of Bobbin Tool Friction Stir Welding of Aluminum Alloys: A Review
}

\author{
Guo-Qing Wang ${ }^{1} \cdot$ Yan-Hua Zhao ${ }^{2} \cdot$ Ying-Ying Tang $^{2}$
}

Received: 11 April 2019 / Revised: 24 May 2019 / Published online: 29 October 2019

(C) The Chinese Society for Metals (CSM) and Springer-Verlag GmbH Germany, part of Springer Nature 2019

\begin{abstract}
Bobbin tool friction stir welding (BT-FSW) is a variant of conventional friction stir welding (FSW). It can be used to weld complex curvature structures and closed sections by adding an extra shoulder instead of a rigid backing anvil, which expands the potential application of FSW in aerospace, railway, automotive and marine industries. BT-FSW has some significant advantages over conventional FSW such as no root flaws, full weld penetration, low stiffness requirements for machines and fixtures, balanced heat input, lower distortion and thus has broad prospects for development. At present, there have been numerous research reports on BT-FSW, but its widespread use is still restricted due to various factors such as tool life, process stability, control complexity and implementation cost. In this paper, the domestic and foreign research progress of BT-FSW is reviewed from four aspects of bobbin tool design and classification, temperature field and flow field during welding, microstructure and mechanical properties of welded joints as well as industrial application, and then the possible research hotspots of BT-FSW in the future are pointed out. This paper mainly aims to help researchers have a comprehensive and in-depth understanding of BT-FSW.
\end{abstract}

Keywords Bobbin tool $\cdot$ Temperature field $\cdot$ Flow field $\cdot$ Microstructure $\cdot$ Mechanical properties $\cdot$ Application

\section{Introduction}

Friction stir welding (FSW) is an advanced and mature solidstate joining technique developed by The Welding Institute (TWI) in 1991 [1], which has demonstrated particular suitability for welding aluminum alloys [2]. It has some significant advantages over conventional fusion welding such as no arc, no fumes and spatter, no solidification defects, low distortion and residual stresses, excellent mechanical properties and thus has been widely employed in aerospace, railway,

Available online at http://link.springer.com/journal/40195

Guo-Qing Wang

guoqing_wang@aliyun.com

Yan-Hua Zhao

zaneyanhua@sohu.com

Ying-Ying Tang

tangying8901@126.com

1 China Academy of Launch Vehicle Technology, Beijing 100076, China

2 Capital Aerospace Machinery Company, Beijing 100076, China automotive and maritime industries [3-6]. Due to the typically high downforce applied during welding, the FSW process is usually performed as a fully mechanized process. A rigid backing plate under the workpiece is indispensable to react the high downforce and prevent the deformation of the workpiece, which directly limits the application of FSW in curved and large structures (e.g., rocket fuel tanks) and closed profiles (e.g., hollow extrusions) where the use of a well-supported backing plate is difficult or impossible [7, 8].

Bobbin tool friction stir welding (BT-FSW) is a variant of conventional FSW and is also called self-reacting FSW or self-support FSW in some literature [9-11]. Compared with the conventional FSW tool composed of only one shoulder and one pin, the bobbin tool has an extra shoulder attached to the tip of the pin, which is known as lower shoulder, as shown in Fig. 1. The lower shoulder replaces a rigid backing anvil used in conventional FSW, which makes BT-FSW capable of welding curved and large structures and closed profiles [12-14]. The use of the two shoulders enables balancing the downward forces generated by an individual shoulder within the tool, but these forces have to be carried by the tool pin, which reduces the stiffness requirements for FSW machines and clamping fixtures but yields a challenge 


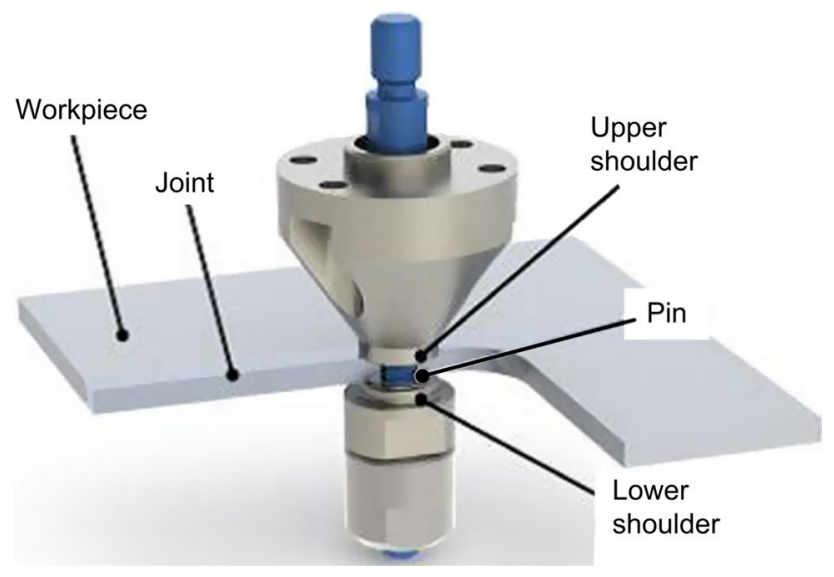

Fig. 1 A representative of bobbin FSW tools [13]

regarding bobbin tool design and material selection. Additionally, the use of the two shoulders avoids root flaws and incomplete weld penetration and also causes much less distortion due to balanced heat input than conventional FSW. For thick section joining, BT-FSW can improve welding efficiency by avoiding multi-pass requirement and permit for an increase in welding speed [15]. These advantages make BT-FSW have broad prospects for development.

BT-FSW process is typically started by traversing the tool into the material from the workpiece edge or from a predrilled pilot hole with an initially slow travel speed until plastic deformation starts, followed by acceleration of the travel speed to the final steady state [16]. To date, there have been a lot of research reports on BT-FSW especially for joining aluminum alloys, but its widespread application is still limited. The possible reasons are summarized as follow [13, 16-19]: (1) The pin part of the bobbin tool experiences multi-axial tension, superimposed torsion and bending during welding and hence pin wear and even fracture sometimes occur; (2) the control system of BT-FSW is more complex and the equipment modification based on the existing FSW machine is expensive; (3) tool entry and exit defects, void defects and process instability especially in thin sheet welding are prone to occur; (4) many pre-weld preparations and post-weld treatments are required. For example, the welding of ring parts requires a predrilled pilot hole and the lower shoulder needs to be withdrawn from the back of the ring parts after welding; (5) many studies on BT-FSW are still in a piecemeal manner, which makes it difficult to integrate the various studies into process models suitable for production engineering.

In this paper, the domestic and foreign research progress of BT-FSW is reviewed from four aspects of bobbin tool design and classification, temperature field and flow field during welding, microstructure and mechanical properties of welded joints as well as industrial application, and then
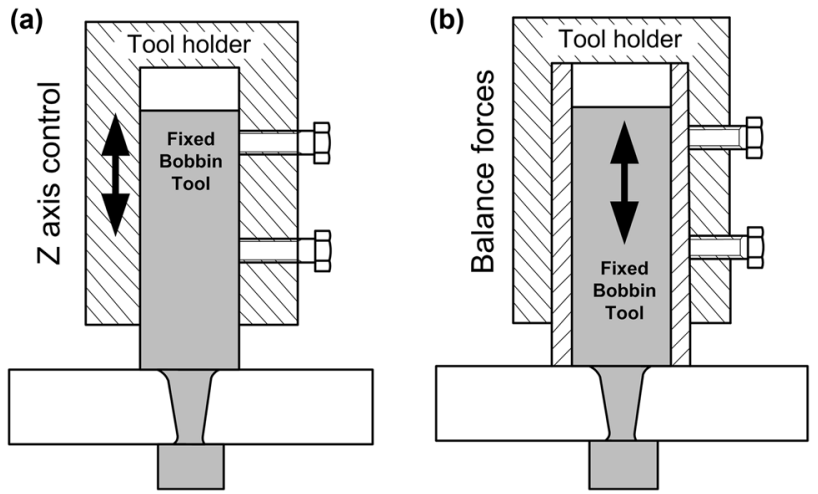

Fig. 2 Two kinds of fixed-gap bobbin tools [16]: a fixed bobbin; b floating bobbin

the possible research hotspots of BT-FSW in the future are pointed out. The purposes of this article are to help researchers have a comprehensive and in-depth understanding of BTFSW and to provide reference for its further development and application promotion.

\section{Bobbin Tool Design and Classification}

The working principle of BT-FSW makes the bobbin tool especially its pin part withstand a more complex stress state than the tool in conventional FSW, which gives rise to a large challenge respecting bobbin tool design and material selection. The design features of the bobbin tool include its shape, size and features on shoulder and pin surfaces. These features directly affect material flow and heat generation during welding and thus have an important influence on weld formation quality. According to available studies, various types of bobbin tools such as fixed-gap type [16], adjustablegap type [20], dual-rotation type [21, 22] and stationaryshoulder type [23] have been developed.

\subsection{Fixed-Gap Bobbin Tool}

The fixed-gap bobbin tool has a fixed distance between the upper and lower shoulders throughout the welding process and can thus only be used for a single thickness of joints. According to $\mathrm{z}$-axis movement, this type of tool can be further classified into fixed bobbin type and floating-bobbin type, as shown in Fig. 2a, b. Unlike the fixed bobbin, the floating bobbin can freely move up and down in a sleeve to find best position to balance the forces acting on the two shoulders during welding, which simplifies process control and greatly reduces the requirement for high machine positional accuracy by improving the tolerance to workpiece thickness variation and component-machine alignment. Figure 3 shows a pinless floating-bobbin tool, which is a 


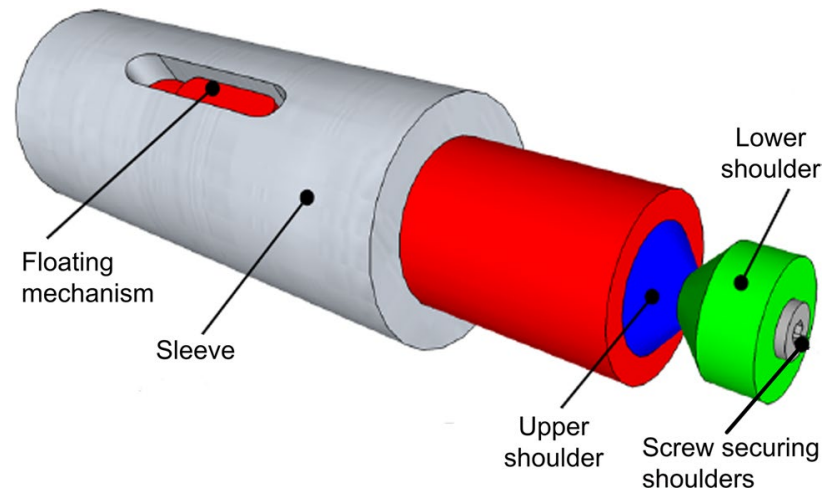

Fig. 3 Pinless floating-bobbin tool [24]

special case of the floating-bobbin tool. Obviously, BT-FSW using this tool design can further improve tolerance to the variation of workpiece thickness.

According to the literature [24, 25], floating-bobbin FSW has been performed on conventional FSW or milling machines for 3- and 5-mm-thick AA6082-T6, but it is not particularly suitable for implementation on the current industrial robots, because the robot lacks stiffness and payload and the combination of high traverse force and spindle torque leads to significant vibration of the robot system, which has detrimental effects on weld formation and bobbin tool life. Due to easy manufacturing and relatively simple control system, the fixed-gap bobbin tool is currently the most widely used tool in BT-FSW. Its main drawback is the lack of control of the force acting between the two shoulders. This force results from the thickness mismatch between the tool gap and the workpiece. It is a function of temperature due to thermal expansion. The change in gap force due to thermal expansion can be very large, which may cause tool fracture and process instability especially in thin sheet welding [13]. Therefore, it is generally necessary to conduct some pre-tests to determine a suitable shoulder gap before performing the formal fixed-gap BT-FSW.

The research on design features of fixed-gap bobbin tools is mainly focused on pin features. Xia et al. [26] studied the effects of cylindrical and tapered pins on weld formation of 30-mm-thick 5A06 aluminum alloy. The result shows that the weld cross section using the tapered pin with grooves presents multilayered onion ring morphology, but the weld cross section using the cylindrical threaded pin has no onion ring morphology, as shown in Fig. 4. This is because the plasticized material flows more turbulently using the cylindrical threaded pin than using the tapered pin with grooves. Sued et al. [19] examined the effects of six different cylindrical pin features shown in Fig. 5 on weld formation and joint properties in BT-FSW of 4-mm-thick 6082-T6 aluminum alloy and found that the pin with four flats provides better joint quality than the pin with threads or grooves. Similarly, Amin and Mohamed [27] studied the effects of five different pin features on mechanical properties of BT-FSW joints of 6.25-mm-thick 6061-T6 aluminum alloy and also found that the cylindrical pin with four flats provides the best joint properties.

There are also a few studies on shoulder features of fixedgap bobbin tools. Flat, concave and convex are commonly used design features regarding the shoulder profile [19]. Sued and Pons [28] recommended flat features for welding thin sections, because it is very difficult to fabricate complicated features in a small gap and different shoulder features have very less efficacy while using for thin materials. Huang et al. [12] developed a bobbin tool composed of a big concave upper shoulder and a small convex lower shoulder for welding aluminum hollow extrusions. The test results indicated that BT-FSW using this shoulder feature can tolerate the slight variation of workpiece thickness and does not need

(a)

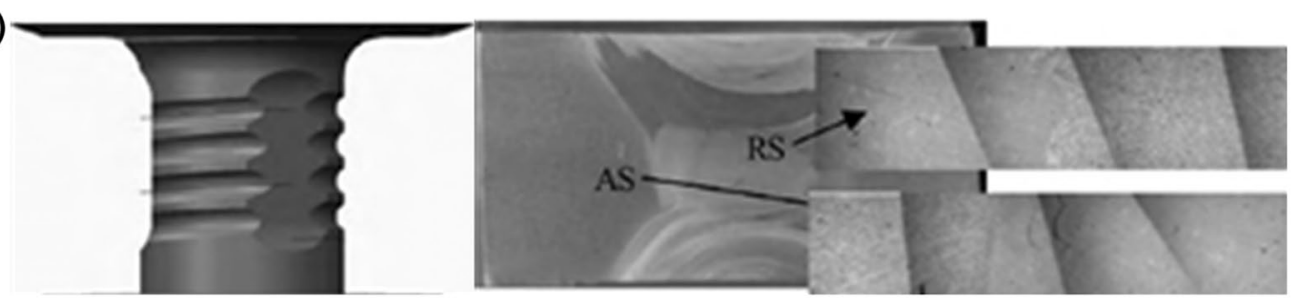

(b)

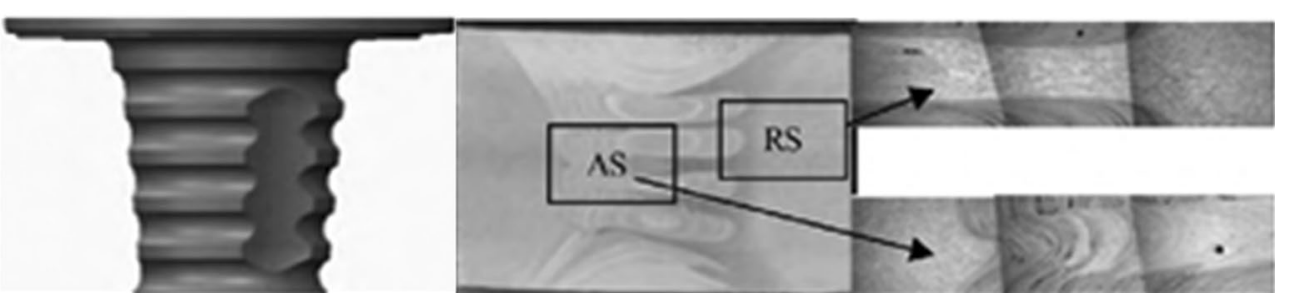

Fig. 4 a Cylindrical threaded pin and its weld cross section; b tapered pin with grooves and its weld cross section [26] 

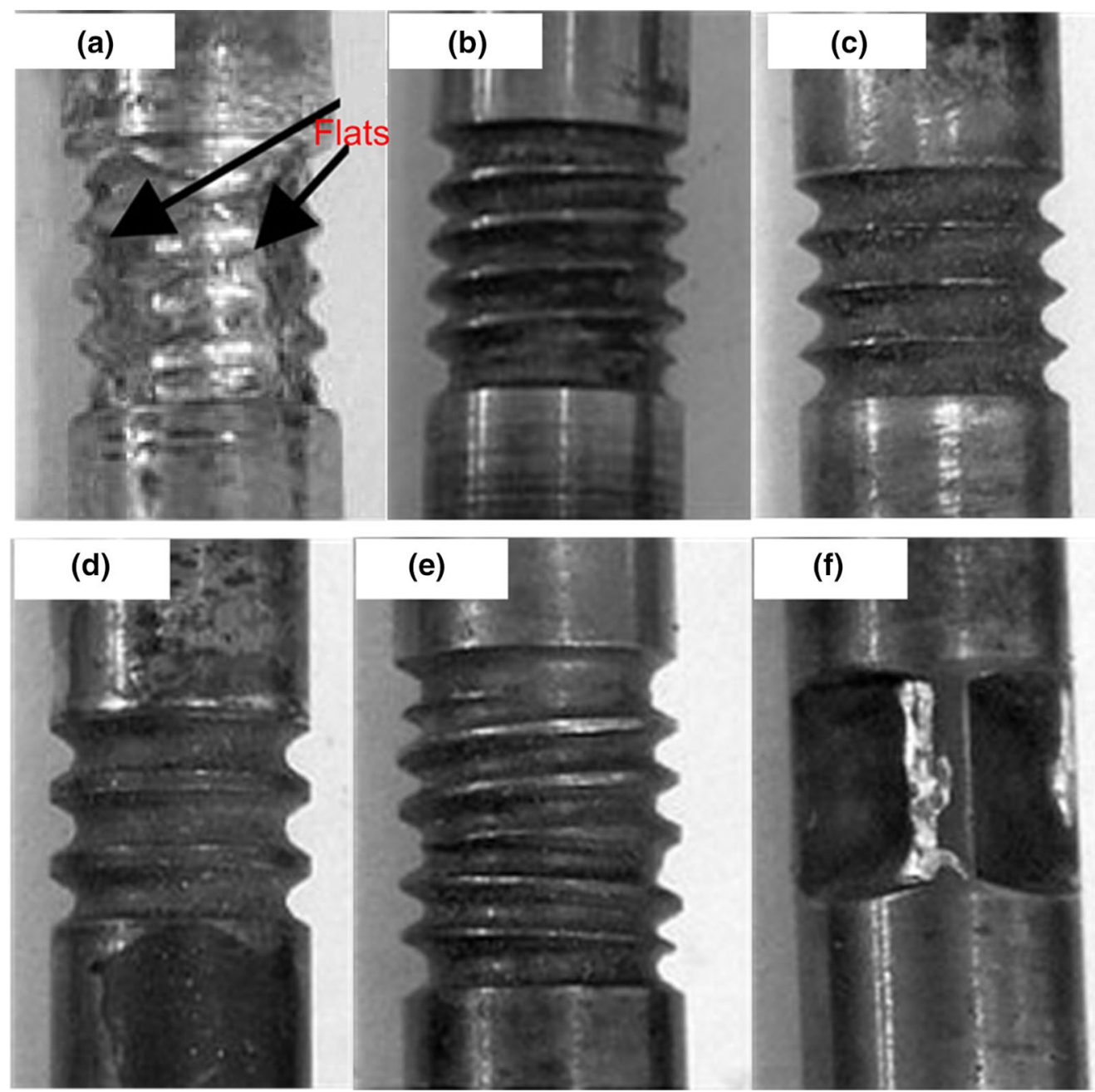

Fig. 5 Features of cylindrical pins [19]: a threaded with 3 flats pin; b threaded pin; $\mathbf{c}$ with grooves and $1.5 \mathrm{~mm}$ pitch; $\mathbf{d}$ with grooves and $2 \mathrm{~mm}$ pitch; e Left Hand and Right Hand threaded pin; 4 flats pin

a predrilled pilot hole, which simplifies the welding process. Moreover, the heat input and the risk of pin breakage during welding can be effectively controlled by changing the sizes of the two shoulders [29]. However, the features on shoulder surfaces such as concentric circles, scroll, grooves and knurling in BT-FSW have not been studied.

\subsection{Adjustable-Gap Bobbin Tool}

For the adjustable-gap (also called adaptive-gap) bobbin tool, the gap between the upper and lower shoulders can be adjusted in real time by position or force control during welding, which accommodates the variation of workpiece thickness caused by thermal expansion and hence reduces the risk of tool fracture and process instability. Also, the adjustable-gap bobbin tool can be used to weld uneven thickness sections.
Figure 6 shows an adjustable-gap bobbin tool developed by Robert Carter and Kirby Lawless of Marshall Space Flight Center [20]. This tool design allows limited rotation of the lower shoulder about the gimbal axes to accommodate local variations in the slope of the back surface of the

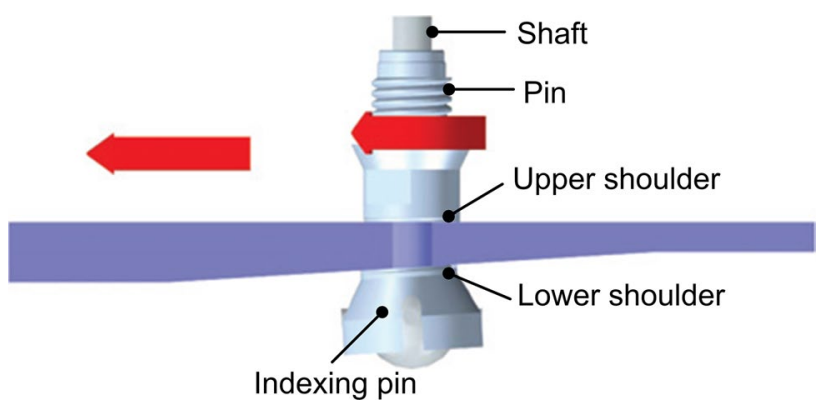

Fig. 6 Adjustable-gap bobbin tool [20] 
workpiece. It has been used to manufacture aircraft components by Airbus in Bremen, Germany and Eclipse in Albuquerque, USA. However, very few details are reported on this technique due to its complex control system. To date, many studies on adjustable-gap BT-FSW of more than 4-mm-thick sheets have been reported, but few reports on adjustable-gap BT-FSW of thin sheets especially below $2 \mathrm{~mm}$ thick, because it is still difficult to ensure process stability during BT-FSW of thin sheets. Therefore, in order to achieve the stable welding of thin sheets, it is necessary to further optimize control strategies of BT-FSW system [20].

\subsection{Dual-Rotation Bobbin Tool}

The dual-rotation bobbin tool (DBT) has a differential in rotation speed and/or direction of the upper and lower shoulders during welding. To avoid void defects and expand the process parameter window of defect-free BT-FSW joints, Wang et al. [21] developed a dual-rotation bobbin tool shown in Fig. 7, whose upper shoulder (US) and lower shoulder (LS) have different rotation speeds but the same rotation direction. Compared with conventional BT-FSW, dual-rotation BT-FSW produces a staggered layer structure and unbalanced force between the US and LS during welding, which makes more sufficient material flow in the thickness direction of welded joints and hence effectively avoids the formation of void defects. Figure 8 shows a counterrotation bobbin tool developed by Nunes [22], whose upper and lower shoulders have the same rotation speed but reverse rotation directions. The reverse rotation of the two shoulders makes the direction of the torque acting on the pin and

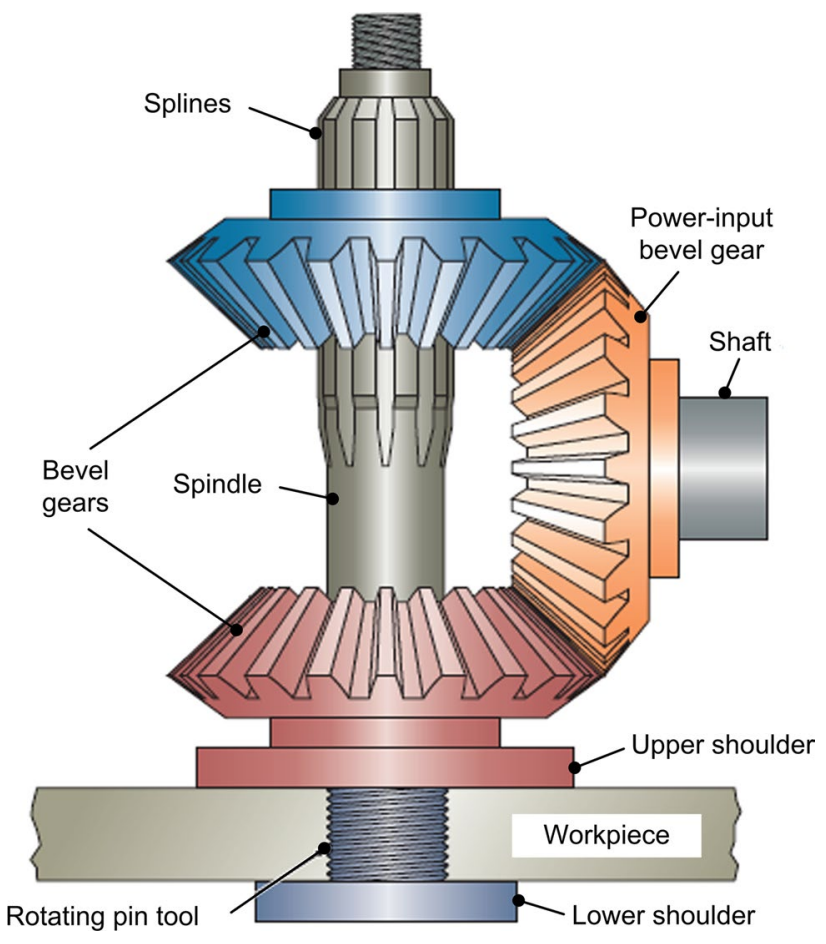

Fig. 8 Counter-rotating bobbin tool [22]

workpiece opposite. Most of the torque offsets each other and the net torque is significantly reduced, which greatly reduces the risk of tool fracture and also reduces the stiffness requirements for clamping fixtures. In addition, Liu et al. [30] conducted some similar research on BT-FSW with different rotation speeds or directions of the two shoulders.

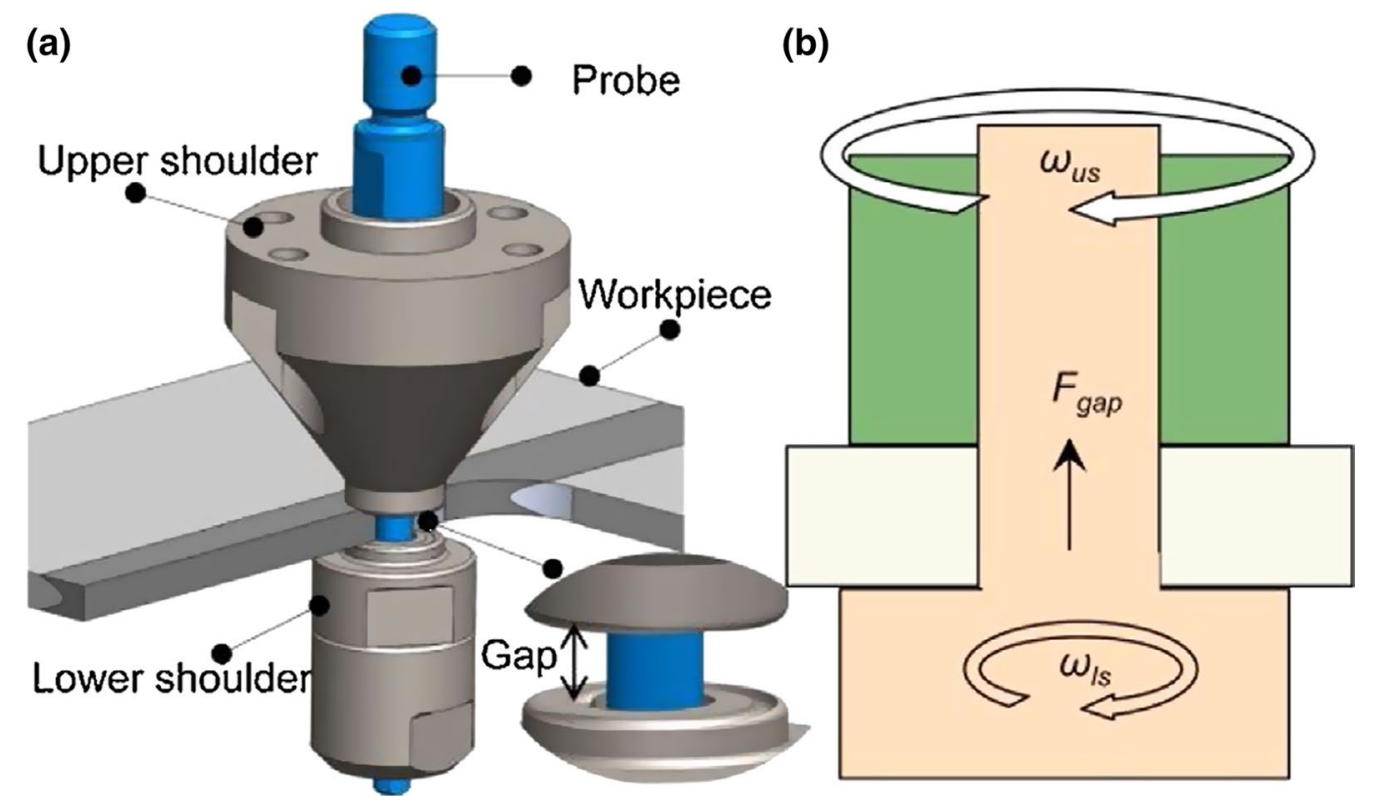

Fig. 7 a Details of the DBT; $\mathbf{b}$ schematic of DBT-FSW [21] 


\subsection{Stationary-Shoulder Bobbin Tool}

Dos Santos and Hilgert from Helmholtz-Gistacht Research Center proposed the concept of stationary-shoulder bobbin tool. Specifically, the upper and lower shoulders of BT-FSW keep stationary throughout the welding process. Although the achievement of full stationary-shoulder BT-FSW has remarkable challenges in terms of bobbin tool design and material selection, the use of partly stationary shoulder tool has confirmed the concept. TWI developed a bobbin FSW tool with a stationary upper shoulder, as shown in Fig. 9 [25]. The stationary upper shoulder provides a smooth surface finish and reduces welding heat input. Its main advantage is increased stability when the weld is performed by a robot. Similar with stationary shoulder FSW, the upper shoulder of BT-FSW slides over relatively cold material during welding and therefore the risk of the tool digging into the plasticized material is greatly reduced. The shoulder acts as a damper for the process, making it much more stable especially during the weld start. Goebel et al. [31] employed BT-FSW with a stationary upper shoulder for joining AA2198-T851 and obtained the similar welding effect.

Tool fracture and process instability especially in thin sheet welding are two main problems in BT-FSW. These two problems can be alleviated more or less by selecting the proper type of bobbin tools under different application conditions. The design features of bobbin tools directly control heat generation, material flow and hence have an important effect on tool life and process stability. However, few studies were reported to improve tool life and process

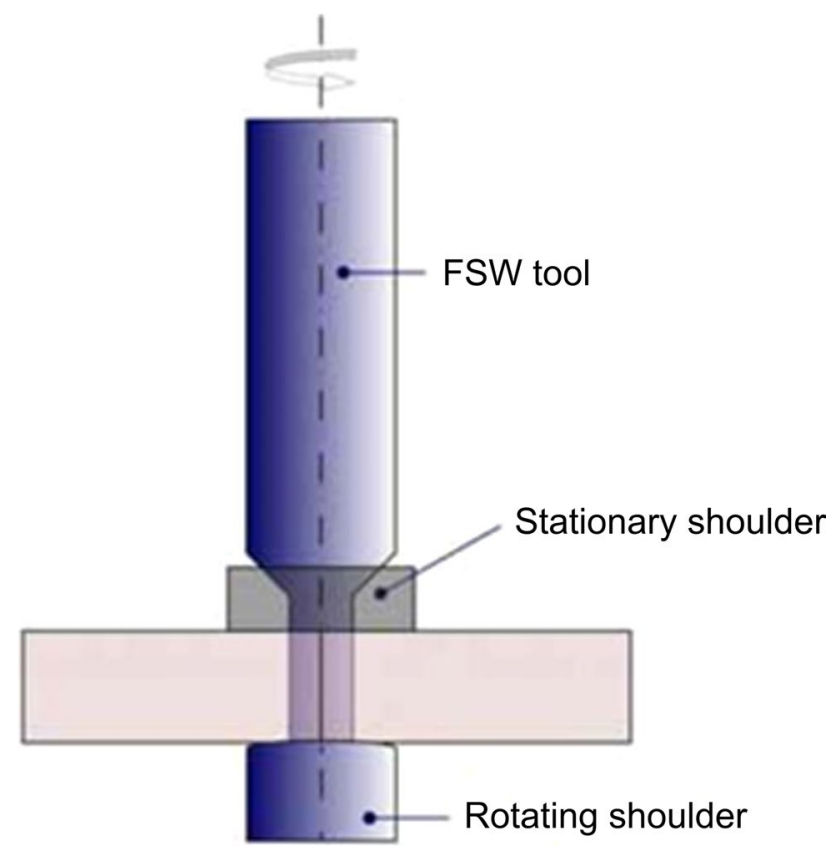

Fig. 9 Semi-stationary shoulder bobbin tool [25] stability by optimizing the design features of bobbin tools. To date, the design and optimization of bobbin tools mainly rely on experience and trials, which is expensive and time consuming. Therefore, the systematic design and optimization of bobbin tools based on numerical simulation and a few experiments will be a research hotspot in the future. Compared with fixed-gap BT-FSW and adjustable-gap BT-FSW, dual-rotation BT-FSW and stationary-shoulder BT-FSW can make better use of the shoulders to regulate material flow and welding heat input and hence will probably become a competitive joining technique in the advanced manufacturing field of the future.

\section{Temperature Field and Flow Field}

BT-FSW process involves complex heat generation and material flow, which directly affects microstructure and mechanical properties of welded joints. Heat generation and material flow during BT-FSW are significantly affected by tool design features, process parameters and mechanical behavior of workpiece materials. Studying the temperature field and flow field of BT-FSW can help in analysis the mechanism of weld formation and also can provide theoretical guidance for tool design, process parameter selection and even new process development.

Li et al. and Zhou [32,33] measured the temperature history of feature points inserted in 6-mm-thick 6082 aluminum alloy plate by thermocouples during BT-FSW. They found that the temperature on the retreating side (RS) of the weld is higher than that on the advancing side (AS), as shown in Fig. 10. The temperature near the lower shoulder is slightly higher than that near the upper shoulder and is much higher than that near the mid-thickness. As welding speed increases, the temperature of all feature points decreases. With the feature points away from the weld centerline, the effect of welding speed on temperature distribution is weakened. Similar results were also reported in the literature [34, 35].

Liu et al. [36] simulated the temperature field of BTFSW of 6-mm-thick 2014 aluminum alloy by using a coupled thermo-mechanical model in DEFORM-3D software. As Fig. 11a shows, the temperature field of the weld cross section presents symmetry approximately about the midthickness of the workpiece. The peak temperature on the RS is about $40{ }^{\circ} \mathrm{C}$ higher than that on the AS. The high temperature zone near the upper and lower shoulders has larger radius than that near the mid-thickness, like an hourglass shape, which is indirectly verified by weld macrographs. According to Wang's simulation results [18], the high temperature zone in horizontal direction is elliptical with the welding direction as the long axis, and the temperature gradient ahead of the pin is greater than that behind the pin, 


\begin{tabular}{|c|c|c|c|}
\hline \multicolumn{4}{|c|}{ Advancing side } \\
\hline $\mathrm{CH} 1 \not$ & $\begin{array}{c}\mathrm{CH} 2 \varnothing \\
\text { direction }\end{array}$ & $\mathrm{CH} 3 \otimes$ & $\mathrm{CH} 4 \not$ \\
\hline $\mathrm{CH} 5 \otimes$ & $\overrightarrow{\mathrm{CH} 6} \not$ & $\begin{array}{l}\mathrm{CH} 7 \varnothing \\
\text { ing side }\end{array}$ & $\mathrm{CH} 8 \not$ \\
\hline
\end{tabular}

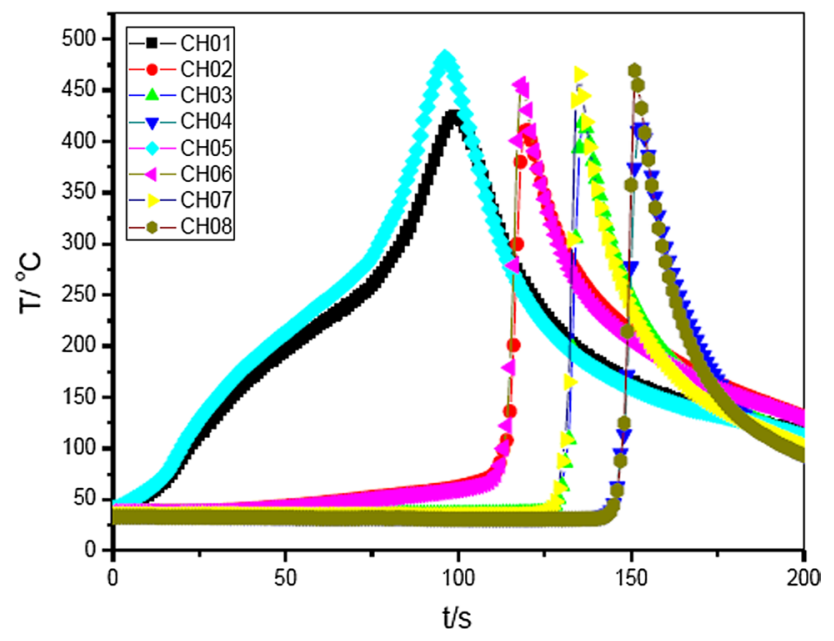

Fig. 10 Temperature history of different feature points [32]
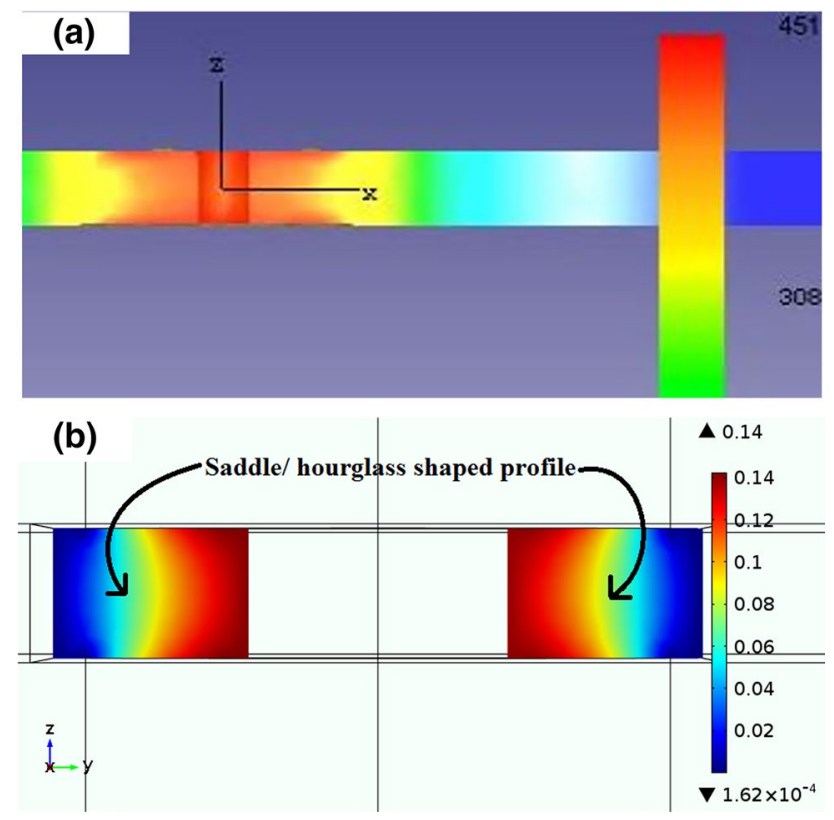

Fig. 11 a Temperature profile across the thickness [36]; b velocity profile in the fluid region [37]

which is same as conventional FSW. According to Zhang's simulation results [34], the upper and lower shoulders are the main source of heat generation, accounting for more than $80 \%$ of the total heat input.

Singh et al. [37] developed a three dimensional (3D) computational fluid dynamics (CFD) model for BT-FSW of AA6061 aluminum alloy using COMSOL Multiphysics software, and a slip-stick contact using a linearly varying slip factor was used in the model. The results show that the flow velocity profile presents an hourglass shape as shown in Fig. 11b, and some material keeps moving with the tool during welding due to the sticking condition. Wang et al. [18] established a 3D coupled Eulerian-Lagrangian thermomechanical model and studied the temperature field and flow field. The results show that the temperature and the effective plastic strain gradient on the AS are higher than those on the RS. A weak material flow area is found at the mid-thickness of workpieces behind the bobbin tool near the AS, as shown in Fig. 12. Fraser et al. [38] established a smooth particle hydrodynamics model of BT-FSW in LS-DYNA software and predicted the temperature field, the torque acting on the tool and the flow field. But, the model did not introduce heat exchange between the mixing tool and the workpiece, and thus there was still a gap between the material flow calculation and experimental results.

Hilgert et al. [39, 40] proposed three thermal 3D models for BT-FSW in COMSOL and Matlab software and the models used thermal pseudo-mechanical (TPM) heat sources. The simulation results indicate that the Eulerian model predicts a steady state. The Lagrangian model is suited for short welds and predicts a transient temperature field. The new moving geometry model can provide transient temperature histories of the tool and workpieces. It can be used for long welds and also can capture the effect of the heating up of the tool. Compared with fully coupled thermo-mechanical arbitrary Lagrangian-Eulerian models, this new model greatly reduces simulation time due to no need of any actual deformation calculation. Further, they presented a 3D CFD model of the material flow around a bobbin tool [41, 42]. In this model, the aluminum in the weld zone was treated as a highly viscous non-Newtonian shear thinning liquid and an analytical shear layer model (ASLM) was used as part of a TPM model. The input parameters for the ASLM were predicted by an artificial neural network trained with the predictions of the CFD model. The simulation results show that the predicted shear layer agrees well with weld macrographs, as shown in Fig. 13. The combination of numerical and analytical modeling can greatly reduce the computational time.

Chen el at. [43] studied the material flow pattern of BTFSW with a symmetrical two-way threaded pin by combination of numerical simulation and tracer material tests. They found that the intermediate metal is pushed to the top and bottom surfaces, presenting a complex flow pattern near the surfaces. Within the shoulder radius range, the local "suctionfilling" cycle appears in front of the pin. Whether the tracer material is in the AS or RS, the part involved in the agitation mostly stays in the AS, as shown in Fig. 14. As welding speed increases, the flow curve radius of plastic metal is smaller and the layered structure which is not welded even appears in the 


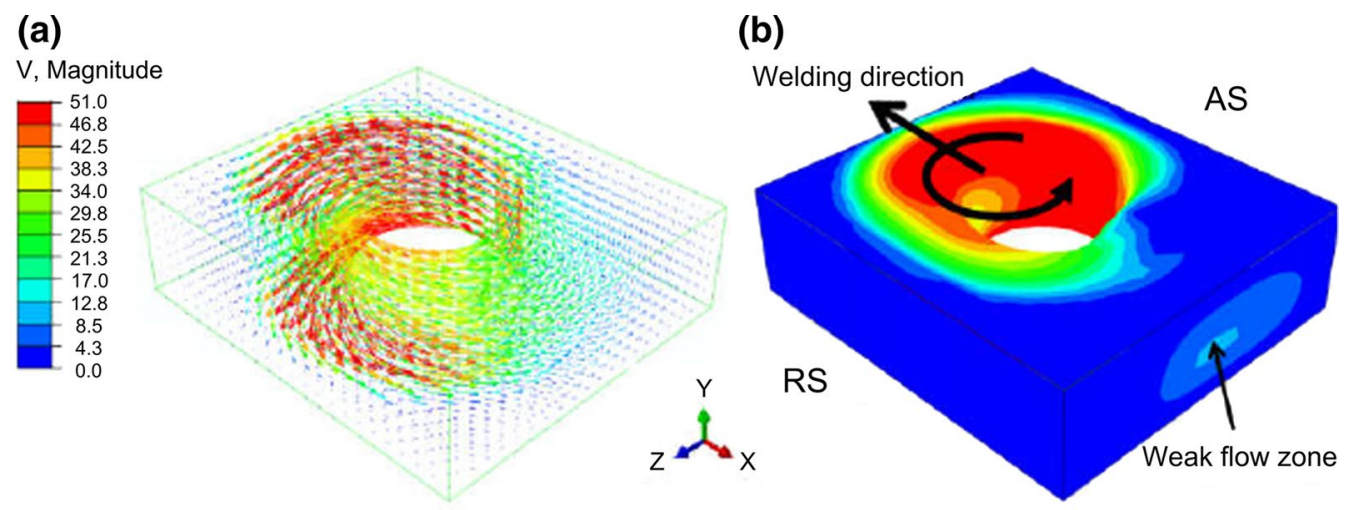

Fig. 12 Calculated velocity field in BT-FSW: a vector map; b contour map [18]
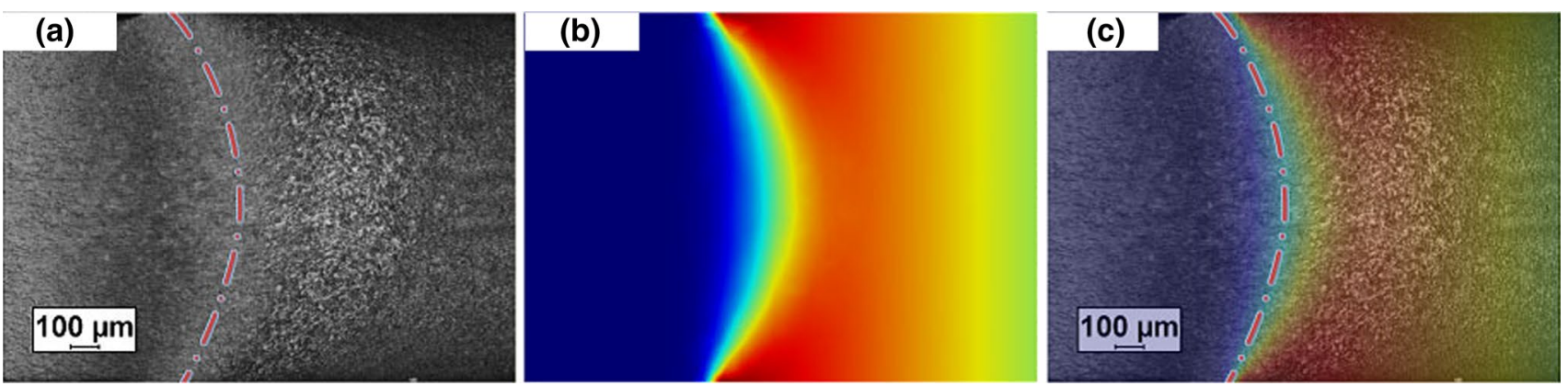

Fig. 13 Comparison between predicted shear layer and weld microstructure [42]: a microstructure at RS; b velocity profile; c combined

AS. With the increase in tool rotation speed, the mobility of stir nugget zone is improved, but the flow curve radius of plastic metal changes a little. But, the insertion of tracer material in the weld line may alter the nature of material flow in the weld because different material flow characteristics of the workpiece and tracer materials introduce additional interfaces [23, 44].

Although there have been a number of experimental studies and computational work performed to analyze the temperature field and flow field of BT-FSW, it is still in its infancy. For different tool design features and process parameters, the temperature field and flow field during BT-FSW also should be simulated and analyzed to help in deeply understanding their effects on weld formation. In the numerical simulation aspect, more accurate and effective techniques still need to be explored regarding calculation methods, material constitutive relationships, contact states and boundary conditions.

\section{Microstructure and Mechanical Properties}

It is well known that microstructure characteristics of welded joints determine their mechanical properties, and hence the variation of mechanical properties can be explained through the corresponding microstructural evolution. This relationship also provides a theoretical basis for optimizing process parameters to improve joint properties.

\subsection{Microstructure}

According to the available literature [15, 45-47], in a typical BT-FSW weld, the same microstructural zones can be observed as in conventional FSW. As shown in Fig. 15(a), these zones include the stirred zone (SZ), the thermomechanically affected zone (TMAZ), the heat-affected zone (HAZ) and the base metal (BM). Unlike the SZ in conventional FSW, the SZ in BT-FSW shows a compressed hourglass shape (Fig. 15a). This suggests that although the tool pin contributes significantly to material flow, its influence is still not as large as that of the shoulders, especially in the case of the tool pin without any features [11, 48]. Different with the highly elongated grains in the BM (Fig. 15b), the SZ (Fig. 15d) has fine equiaxed recrystallised grains due to experiencing the highest strain rates and peak temperatures during welding. The TMAZ (Fig. 15c) has mixed rotated elongated grains and equiaxed grains (i.e., partially recrystallized grains) due to experiencing medium strain rates and high temperatures during welding. The HAZ only 
(a)

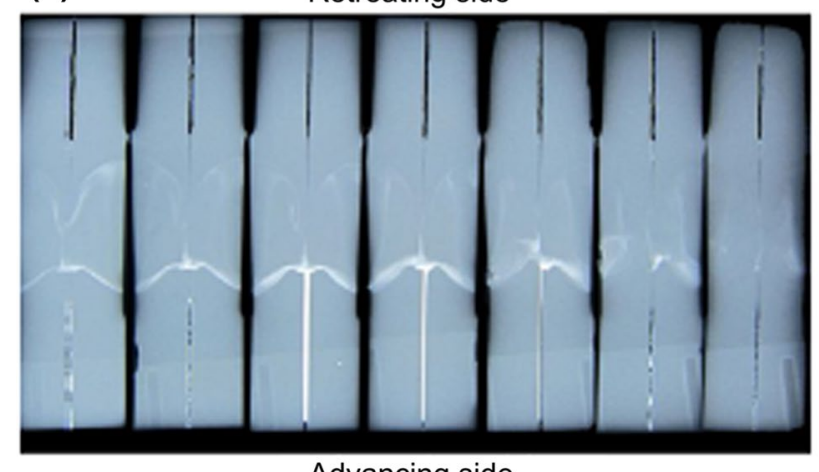

Advancing side

(b)

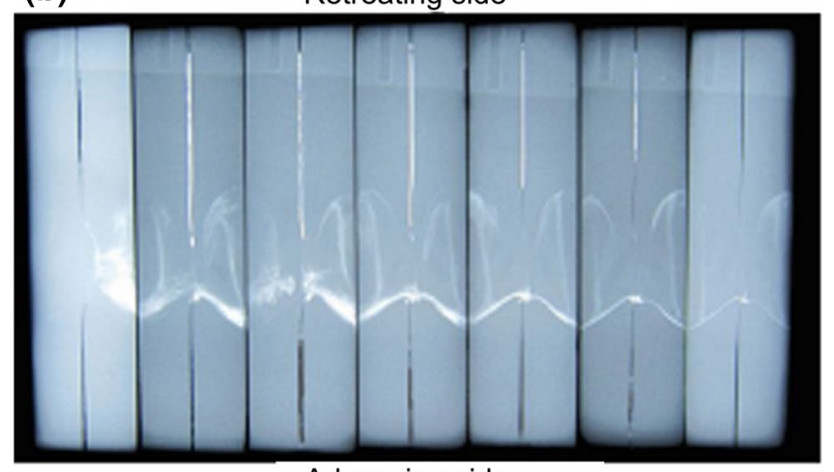

Advancing side

Fig. 14 X-ray pictures of weld cross sections, tracer material placed horizontally in the a AS, b RS [43]

experiences the thermal cycle, and no plastic deformation occurs during welding; hence, it retains the same grain structure as the BM. In addition, a sharp transition can be seen between the TMAZ and SZ on the AS while a much more diffuse interface on the RS is observed (Fig. 15a), which is related to different material flow conditions on the two sides. A special region on the AS of the SZ (called band pattern in the literature [29,49]) shows weld discontinuity in terms of texture development, which is related to special material flow behavior in BT-FSW. Shen et al. [48] pointed out that this weld discontinuity can be eliminated by using counterrotation BT-FSW.

Liu et al. [29] investigated the microstructure of BT-FSW joints of 6061-T6 aluminum alloy and found that the grain size of the SZ increases with the increase in welding speed, but the grain size of the HAZ changes a little. The strengthening metastable precipitates were all diminished in the SZ and TMAZ. The literature [50] reported that the width of the SZ decreases with the increase in welding speed. Similarly, Hou et al. [51] also studied the microstructure of BT-FSW joints of 6061-T6 aluminum alloy. They concluded that, with the increase in rotation speed, the grain size and dislocation density in the SZ increase and all metastable precipitates in the SZ are also diminished. Wang et al. [15] analyzed the microstructure of BT-FSW joints of Al-Li alloy. It is concluded that, as rotation speed increases, the grain size of the SZ increases and the density of strengthening particles decreases. Zhou et al. [52] observed the microstructure of BT-FSW joints of Al-Mg-Si alloy. As a result, void defects were observed in the weld produced at the low rotation speed, and BT-FSW produced much refined microstructure accompanied by dispersion and dissolution of precipitated phases. But, as rotation speed increases, the grain size of the SZ changes little and more coarse microstructure was found in the TMAZ and HAZ. Zhang et al. [53] studied the microstructure of BT-FSW joints of 2A14-T6 aluminum alloy. The grains of the upper layer are smaller than those of the lower layer in the SZ, which results from higher heat dissipation through the upper shoulder. An ellipse-shaped region and a triangle-shaped region characterized by large elongated grain structures are found in the middle layer of the $\mathrm{SZ}$ as shown in Fig. 16. The reason is insufficient material plastic deformation caused by the flat feature of the tool pin. Esmaily et al. [54] reported that the average grain size of the AS is much greater than that of the RS in BT-FSW joints of 10-mm-thick AA6005-T6, which is related to temperature distribution on the two sides. Goebel et al. [31] performed the stationary upper shoulder BT-FSW $\left(\mathrm{SS}_{\mathrm{U}} \mathrm{BT}\right.$-FSW) of AA2198-T851. They found the material flow direction toward the stationary upper shoulder and the macrostructure presents an asymmetrical shape widening up toward the rotating lower shoulder, as shown in Fig. 17. When improper process parameters were used, the location of volumetric defects in $\mathrm{SS}_{\mathrm{U}} \mathrm{BT}$-FSW is close to the sheet surface on the AS. This is different with the location of void defects in BTFSW but is considered advantageous because these defects are easily detected and removed. Above discussion clearly indicates that the morphologies and grain sizes of BT-FSW joints are significantly affected by multiple factors including process parameters and tool design features.

Joint line remnant (JLR, also called Lazy S in some literature $[46,55])$ is often observed in the FSW joints of aluminum alloys and interpreted as remnant oxide films originated from the butt interface during welding. The JLR seriously reduces the mechanical properties of FSW joints of heat-treatable aluminum alloys and also causes preferential etching. Hence, it is undesirable. Wang et al. [15] studied the JLR in BT-FSW joints of Al-Li alloy and found that it exists in all etched welds. As rotation speed increases, the JLR is compressed remarkably in the shoulder-dominated zone (SDZ) while a less change occurs in the probe-significant and shoulder-partial dominated zone (PSZ) with a tendency to shift toward the RS, as shown in Fig. 18.

Threadgill et al. [14] identified the crystallographic texture of bobbin tool friction stir welds of 25 -mm-thick 6082-T6 aluminum alloy. The results show that the welds exhibit a single-shear texture, but the shear plane and its 

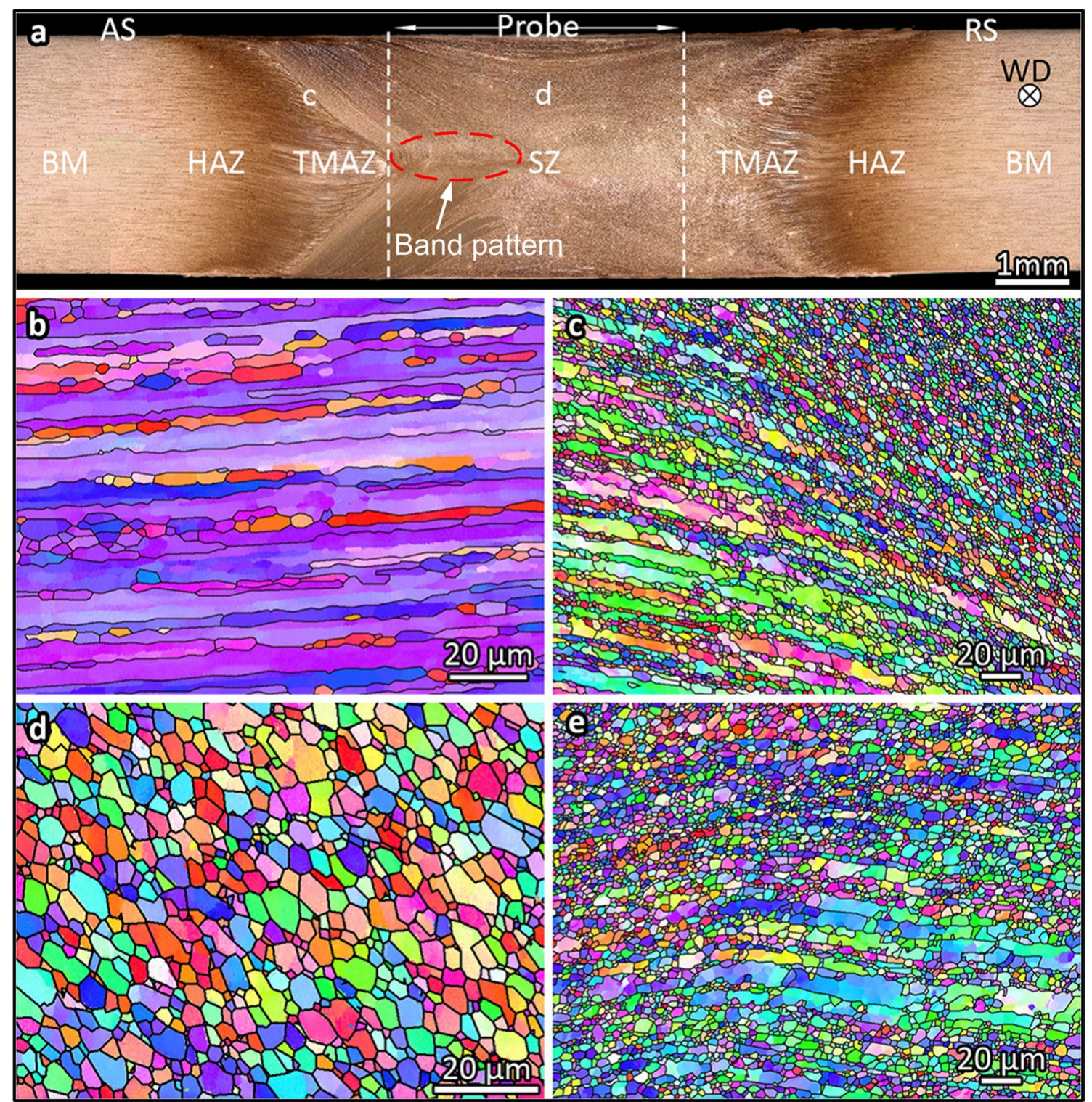

Fig. 15 a A macrograph showing a typical BT-FSW joint overlaid with the probe profile; EBSD micrographs showing the grain morphologies of b the BM; $\mathbf{c}$ the TMAZ on the AS; $\mathbf{d}$ the SZ; e the TMAZ on the RS [15]

normal plane are dominated by the shoulders and the tool pin. In the shoulder-dominated zone, the AS texture mainly focuses on the (001) and (111) crystal planes, whereas the RS texture mainly focuses on the (110) crystal plane. In the pin-dominated zone, the RS exhibits the multi-directional mixed texture, while the AS only exhibits a weak singleshear texture.

\subsection{Mechanical Properties}

The studies on mechanical properties of BT-FSW joints are mainly focused on 2xxx series and 6xxx series aluminum alloys. Zhang et al. [56] and Lafly et al. [57] conducted a comparative study of conventional and bobbin tool FSW of 5-mm-thick AA2219-T4 and 6-mm-thick AA6056, respectively. The results indicate that tensile strength and elongation of joints are slightly lower for BT-FSW. However, some researchers drew different conclusions. Esmaily et al. [58] compared the conventional and bobbin tool FSW of 10-mm-thick extruded AA6005-T6 profiles and found that the BT-FSW joints have a finer grain structure, higher hardness values and slightly higher ultimate strengths. Marie et al. [59] performed the BT-FSW of 6056-T78 and 7449 aluminum alloys and pinpointed that the BT-FSW seemed to be better for medium and thick sections than for thin materials. The possible reasons are as follows: For thin sections, 


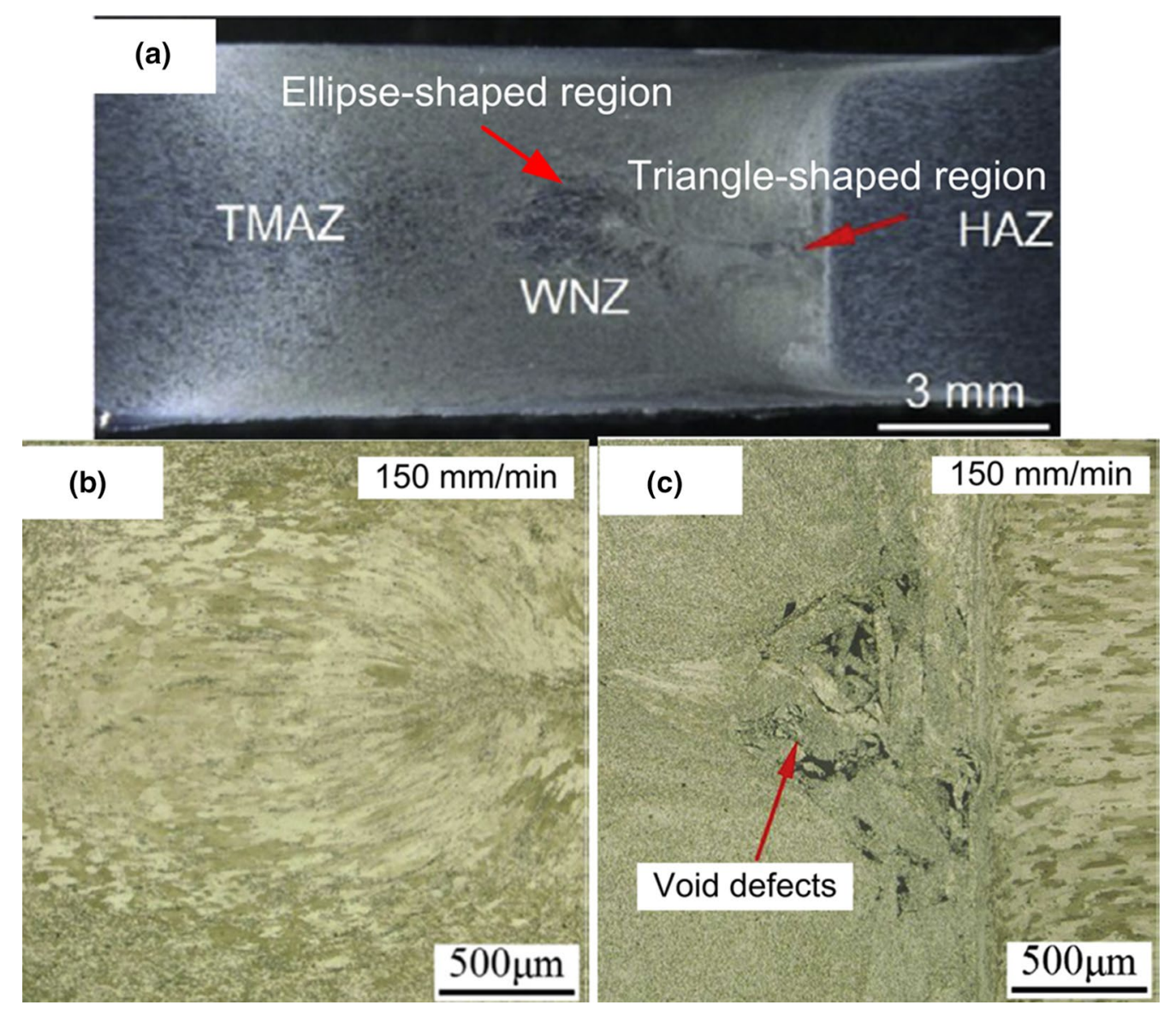

Fig. 16 a Weld cross sections of BT-FSW joints; grain morphologies of $\mathbf{b}$ ellipse-shaped region $\mathbf{c}$ triangle-shaped region [53]

the structural non-uniformity in the thickness direction of FSW joints is not evident, while the larger heat input of BTFSW makes welded joints soften. Therefore, the BT-FSW joints have worse mechanical properties than the FSW joints for thin section welding. For thick sections, the FSW joints show the evident structural non-uniformity in the thickness direction, which tends to cause stress concentration and hence reduces joint properties. Comparatively speaking, the BT-FSW joints have good structural uniformity in the thickness direction. Hence, the BT-FSW joints have better mechanical properties than the FSW joints for thick section welding.

Liu et al. [29] studied the mechanical properties of BTFSW joints of 6061-T6 aluminum alloy and found that the tensile strength of defect-free joints increases with the increase in welding speed. The tensile fracture location is mainly in the HAZ adjacent to the TMAZ on the AS. Zhang et al. [53] examined the mechanical properties of BT-FSW joints of 2A14-T6 aluminum alloy. They reported that, as welding speed increases, the joint strength firstly increases to a peak and then shows a sharp decrease due to the occurrence of void defects. Wang et al. [15] investigated the mechanical properties of BT-FSW joints of Al-Li alloy. They found that, as rotation speed increases, the joint tensile strength also firstly increases to a peak and then shows a sharp decrease due to the occurrence of void defects. According to the cracking initiation site, there are three typical fracture modes. The most frequent fracture mode changes with the increase in rotation speed, as shown in Fig. 19. For various aluminum alloys, the ultimate strength and elongation of reported BT-FSW joints are summarized in Table 1.

As shown in Fig. 20, at each welding speed, the hardness distributions are nearly the same in the upper, middle, lower layers of BT-FSW joints, indicating through-thickness homogeneity of mechanical properties. Also, the occurrence of insufficiently stirred regions does not cause a significant variation in hardness distribution at the middle layer of the SZ [53]. As welding or rotation speed increases, the softest region shrinks and shifts outward, the average hardness of the SZ increases and the hardness distribution along the weld cross section changes from the U-shaped to $\mathrm{W}$-shaped (Fig. 20) [27, 53]. The similar results were also reported in the literature [31, 54, 63, 64]. 


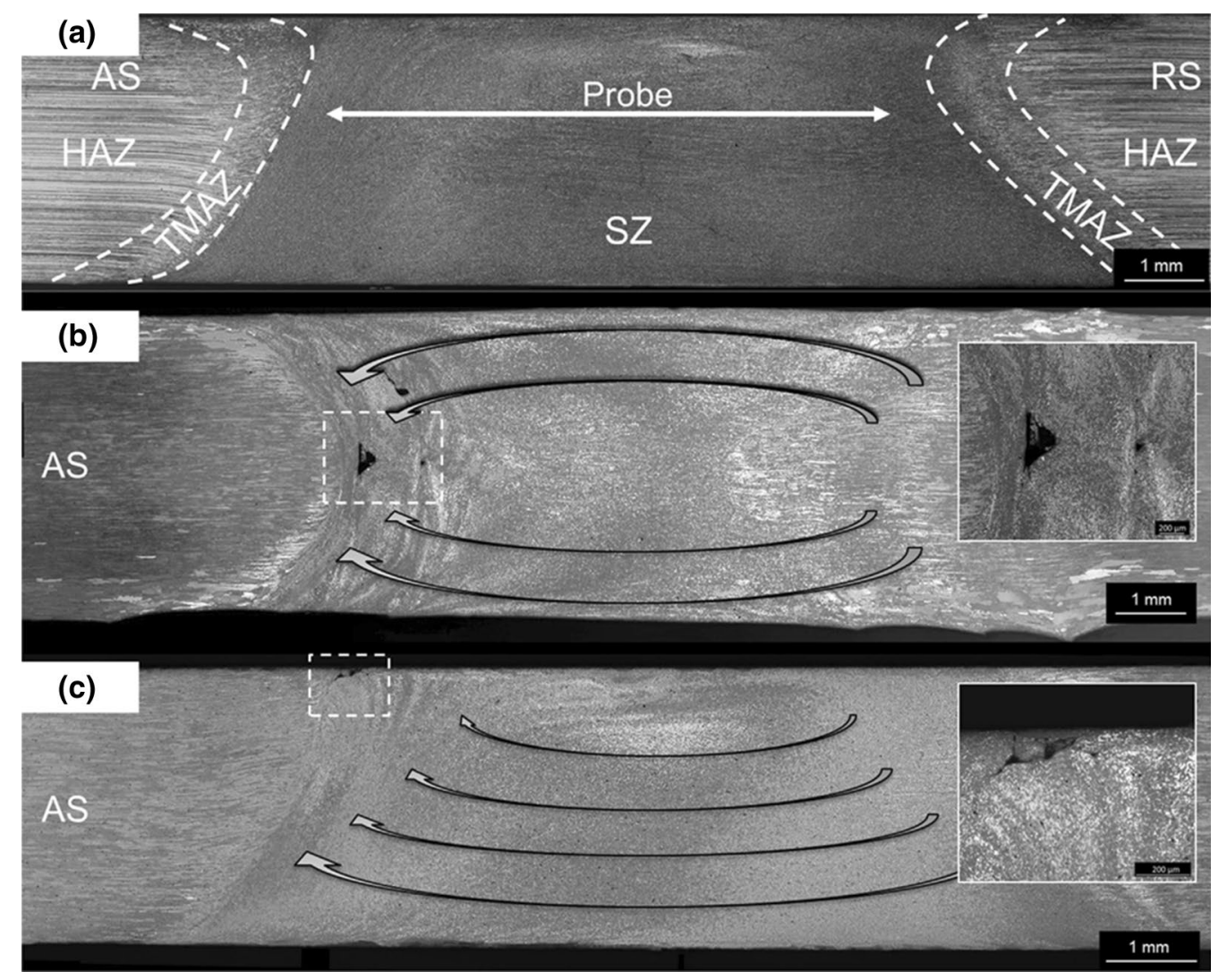

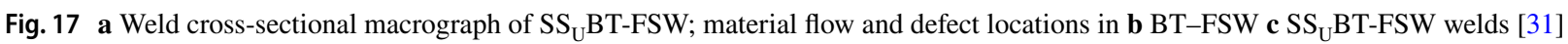

Band pattern, Lazy S and void defects are three common phenomena that need special attention in BT-FSW welds due to significant unfavorable effects on the mechanical properties of joints. At present, most of the research focuses on the influence of process parameters on microstructure and mechanical properties of BT-FSW joints, while only few studies involve the effects of the type, shape and size of bobbin tools. In addition, the studies on microstructure and mechanical properties of BT-FSW joints are mainly focused on aluminum alloys, while few studies have been reported on BT-FSW joints of other materials. Therefore, the effects of the type, shape and size of bobbin tools on microstructure and mechanical properties of BT-FSW joints and the BT-FSW of other materials will be probably two research hotspots in the future.

\section{Industrial Application}

In the last two decades, BT-FSW has gained increasing attention at home and abroad and has been applied in some industrial products such as rockets, aircrafts, ships, automobiles, high-speed trains and pressure vessels.
BT-FSW has been used to aerospace structures in USA since the late 1990s and early 2000s when Boeing Company put FSW into production of Delta series rockets with purpose of avoiding welding defects in conventional fusion welding of fuel ranks of AA2219. Boeing Company performed the longitudinal and circumferential welds of the fuel ranks of Delta II and IV rockets using ESAB SuperStir ${ }^{\mathrm{TM}}$ machine with a bobbin tool and a retractable tool pin [3]. In the program of Ares series propellant tanks, MTS Systems Corporation supplied a Robotic Weld Tool (RWT) which enables performing both conventional and self-reacting FSW on complex curvature tank structures [65]. The RWT is 7 -axis machine tool which has 3 -axis horizontal traveling column with retractable boom, 2-axis roll and pitch assembly positioned on the end of the boom as well as rotary turntable that can both slew and slide. National Aeronautics and Space Administration (NASA) used the RWT to implement the circumferential weld of Y-Ring to tank dome body, as shown in Fig. 21 [66]. Also, MTS Systems Corporation further developed the I-STIM Aero system with three tooling types of fixed pin tool, adjustable pin tool and self-reacting pin tool. This I-STIR Aero system can accommodate both linear and complex, nonlinear contour weld configurations and has 

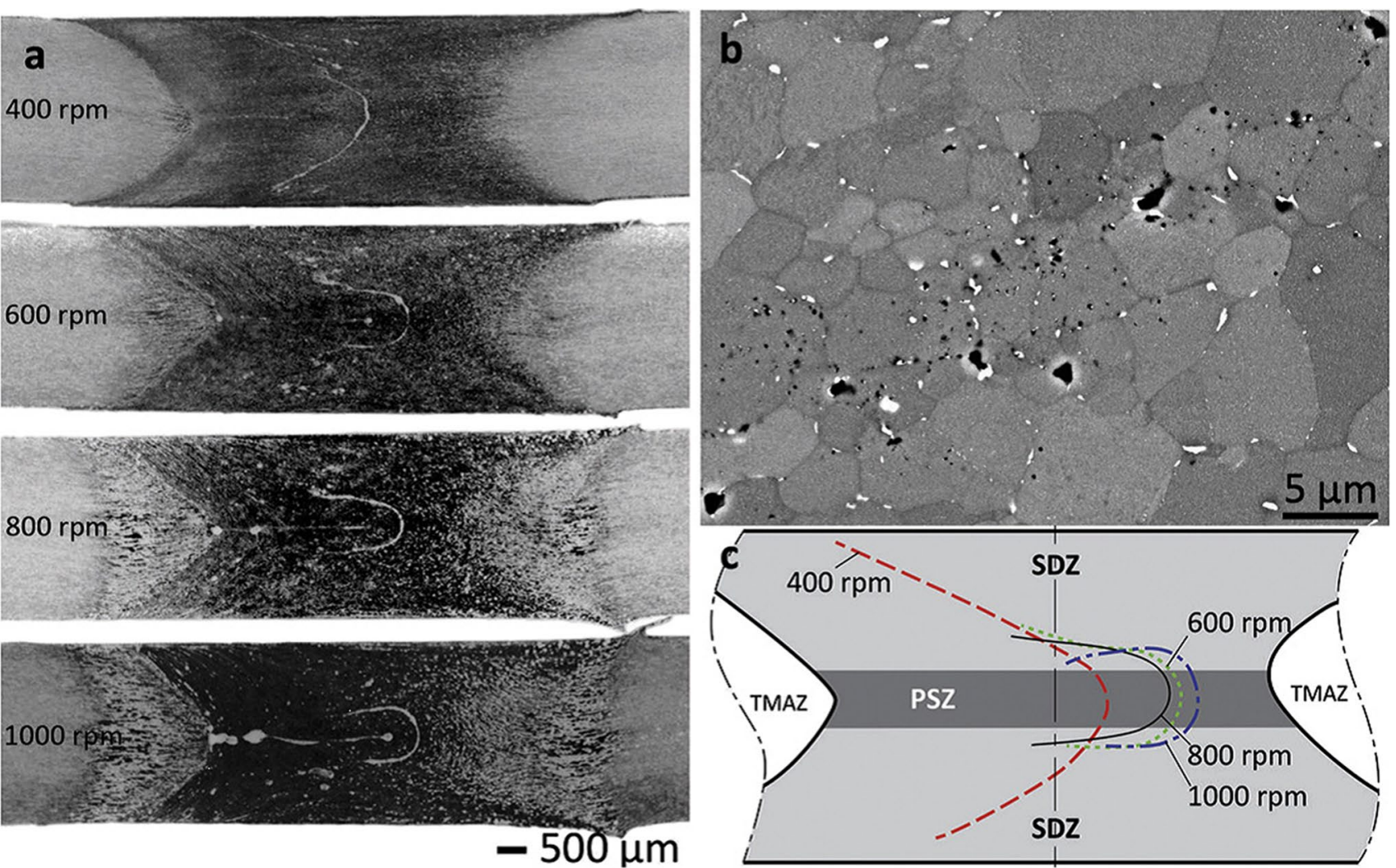

Fig. 18 a Negative optical macrographs of joints produced at different rotation speeds, after being etched by a $2 \% \mathrm{NaOH}$ solution; b a backscattered electron micrograph showing the detail of the JLR region, without etching; $\mathbf{c}$ a schematic diagram showing the influence of the rotation speed on the position and morphology of the JLR. [15]
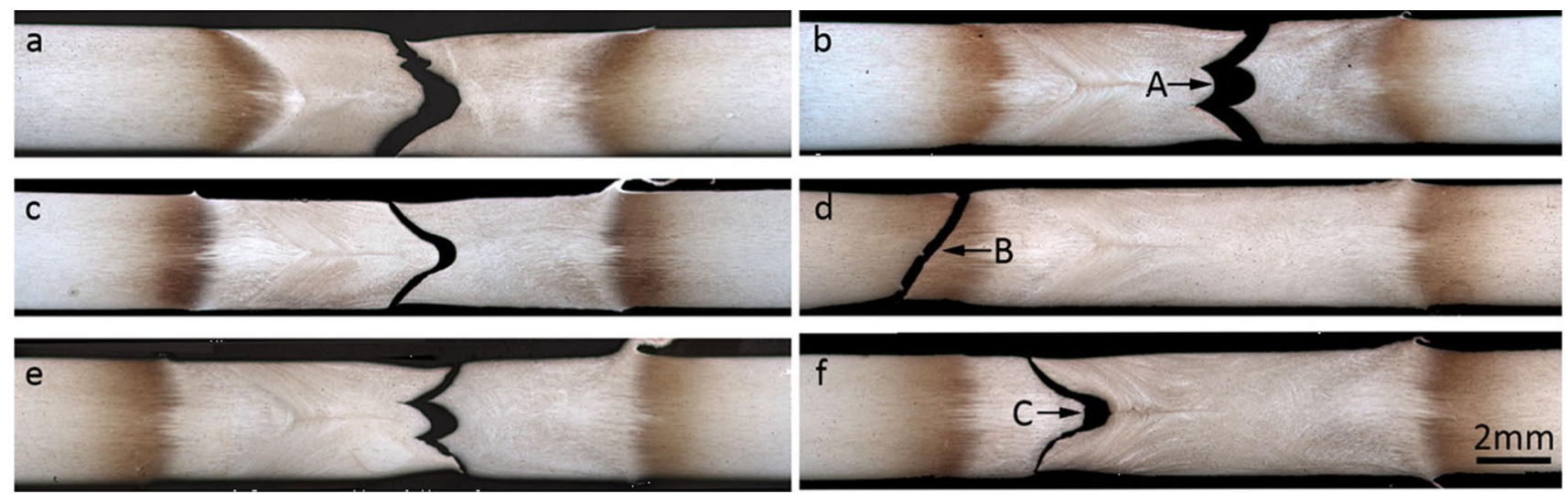

Fig. 19 Typical fracture locations of joints at different rotation speeds (rpm): a 400; b 600; c, d 800; e, f 1000 [15]

been employed in the Eclipse 500 jet aircraft. In addition, NASA also applied BT-FSW technique to the circumferential welds of the Orion crew module and the propellant tank of 8.4 m-diameter Space Launch System [67]. In Japan, Mitsubishi Corporation used BT-FSW technique to complete the circumferential weld of H-IIB rocket tanks [65].
As part of the US Navy Man Tech program, Kevin et al. [68] used low-cost FSW machine with fixed-gap bobbin tool to produce and test a number of large, integrally stiffened panels of 5xxx series and 6xxx series aluminum extrusions below about $6 \mathrm{~mm}$ thick, as shown in Fig. 22. The LC-FSW machine is developed by Concurrent Technologies Corporation in response to a need for low-cost Navy shipbuilding 
Table 1 Tensile properties of BT-FSW joints of various aluminum alloys

\begin{tabular}{lllllll}
\hline $\begin{array}{l}\text { Base materials } \\
(\mathrm{BM})\end{array}$ & $\begin{array}{l}\text { Thickness } \\
(\mathrm{mm})\end{array}$ & $\begin{array}{l}\text { Ultimate strength } \\
(\mathrm{MPa})\end{array}$ & $\begin{array}{l}\text { Joint efficiency } \\
\text { = Joint/BM } \\
(\%)\end{array}$ & Elongation (\%) & References \\
\cline { 2 - 5 } & & $\mathrm{BM}$ & Joint & & 5.1 & {$[53]$} \\
\hline 2A14-T6 & 6 & 460 & 345 & 75 & 10.2 & {$[56]$} \\
2219-T4 & 6 & 420 & 295 & 77 & 7.1 & {$[59]$} \\
2219-T87 & 4 & 459 & 331 & 77 & 3.58 & {$[60]$} \\
2024-T3 & 4 & 469 & 375 & 80 & 16 & {$[19]$} \\
6082-T6 & 4 & 290 & 198 & 68.3 & 10.3 & {$[51]$} \\
6061-T6 & 4 & 284 & 187 & 66 & 1.1 & {$[57]$} \\
6056-T78 & 4 & 322 & 257 & 80 & 9.2 & {$[61]$} \\
6061-T651 & 8 & 290 & 243 & 83.7 & 11.1 & {$[62]$} \\
6061-T6 & 4 & 284 & 196 & 69 & \\
\hline
\end{tabular}

(a)

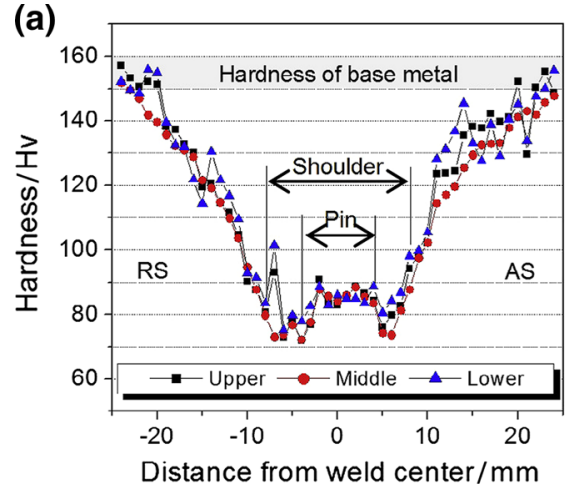

(b)

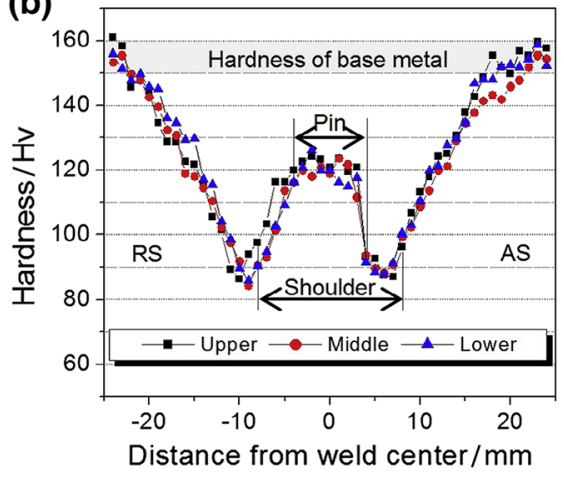

(c)

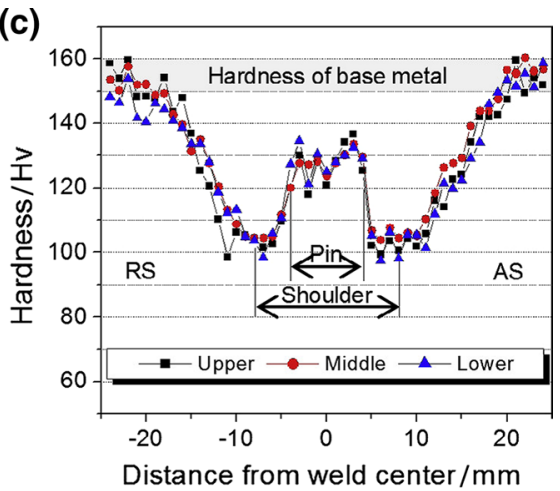

Fig. 20 Hardness distributions of the BT-FSW joints at different welding speeds ( $\mathrm{mm} / \mathrm{min}$ ) [53]: a 50; b 100; c 150

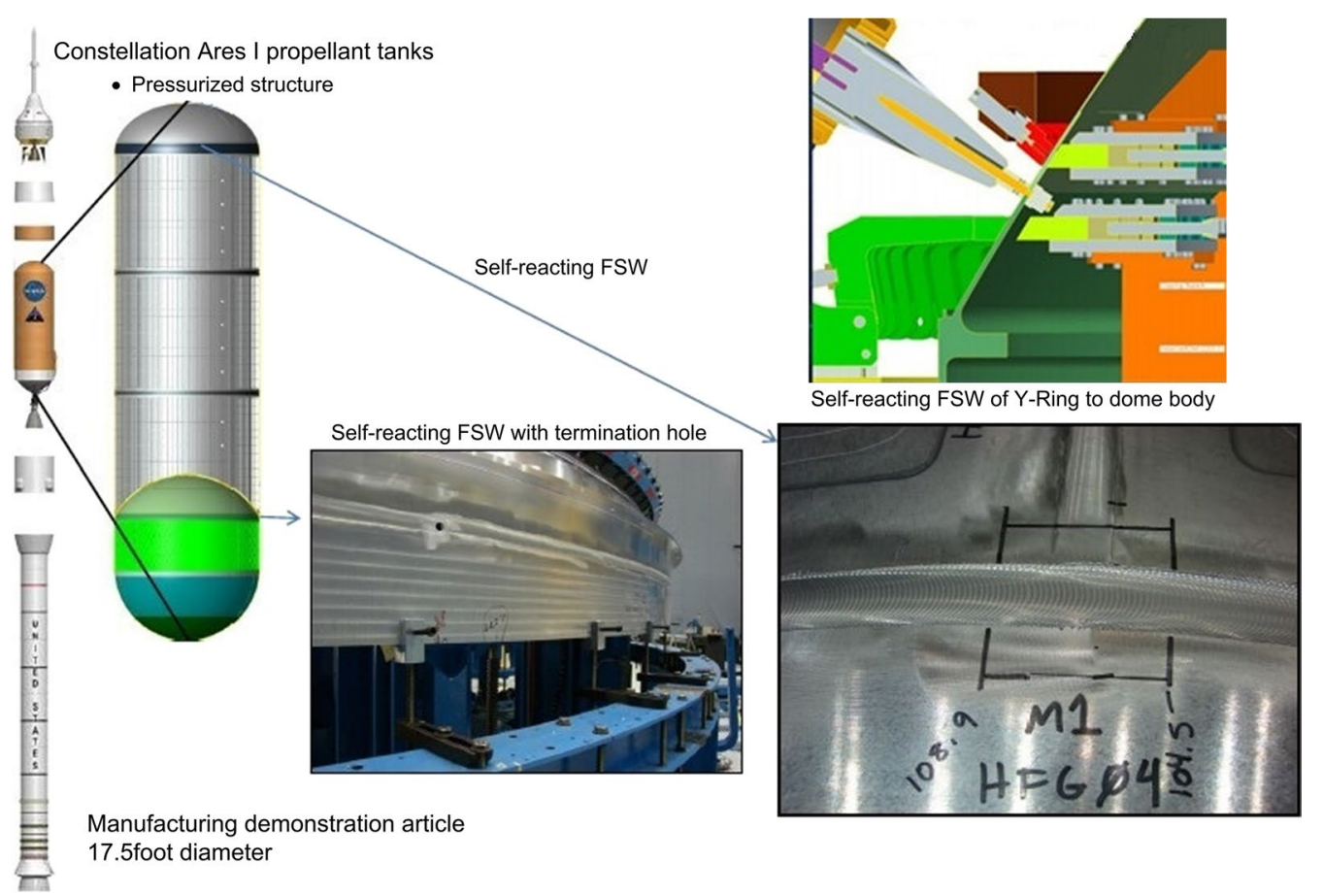

Fig. 21 Robotic Weld Tool used for welding of Constellation Ares I Propellant Tanks [66] 
applications. The panel as shown in Fig. 22 is $6.1 \mathrm{~m}$ long by $3 \mathrm{~m}$ wide and is produced with less than $2 \mathrm{~mm}$ trueposition tolerance in stiffener spacing over the width of the panel, meeting end-user requirements. Nippon Light Metal Co., Ltd. in Japan was reported to use the BT-FSW technique to weld the sidewall panels on car body [69]. TWI has realized the BT-FSW of 3-25-mm-thick aluminum alloy sheets and has successfully used BT-FSW technique to join hollow profiles in high-speed train manufacturing [29]. In production of Chinese "Fuxing" high-speed trains, BT-FSW technique was also applied when joining the flat roof and bottom plate of a carriage. As shown in Fig. 23, the flat roof is well welded using a bobbin FSW tool whose two shoulders are designed with spiral grooves [70]. Dalder et al. [71] used BT-FSW technique to assemble thick-walled AA2219 pressure vessels, which consists of two hemispheres with an inside diameter of $1 \mathrm{~m}$ and a wall-thickness of $3.81 \mathrm{~cm}$. The results of straight-beam ultrasonic examination and phasedarray ultrasonic examination demonstrated that the BT-FSW joints were satisfactory.

Compared with conventional FSW, BT-FSW has not yet been fully developed and applied at present due to various

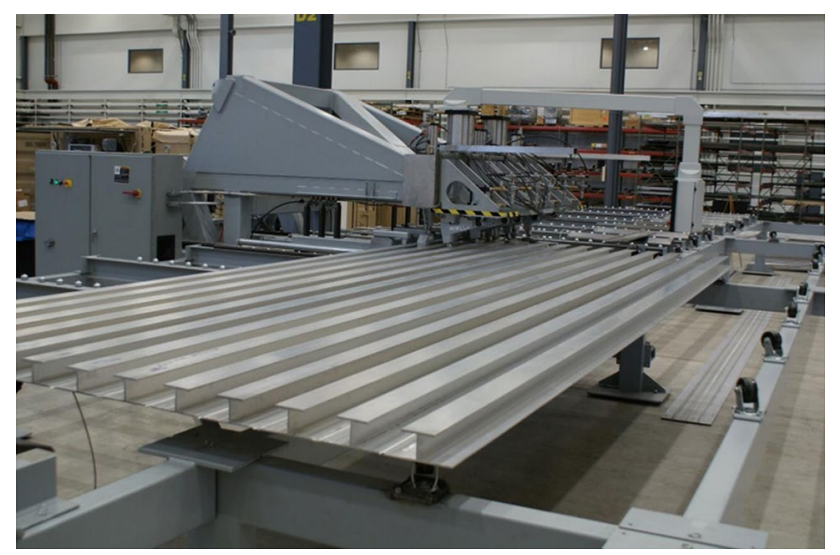

Fig. 22 LC-FSW machine and welded panel [68] factors such as tool life, process stability, control complexity, implementation cost. With the continuous breakthrough of BT-FSW technique, it still has broad prospects for development and application due to its some special advantages over conventional FSW such as no root flaws, full weld penetration, lower stiffness requirements for machines and fixtures, balanced heat input, lower distortion. In China, the basic research and engineering application of BT-FSW is in its infancy. In order to achieve the mature application of BTFSW in the manufacture of rocket fuel tanks, it still needs to carry out a lot of research.

\section{Summary and Outlook}

The two shoulder configuration makes BT-FSW have some special advantages over conventional FSW such as no need of a rigid backing plate, no root flaws, full weld penetration, balanced heat input, lower distortion. It expands the application of FSW in complex curvature structures and closed sections and thus has broad prospects for development. To date, researchers have developed various bobbin tools including fixed-gap type, adjustable-gap type, dual-rotation type and stationary-shoulder type. Generally, BT-FSW is not particularly suitable for implementation on the current industrial robots due to limited stiffness and payload. At present, the design and optimization of bobbin tools are mainly based on experience and trials, and the effects of bobbin tool features especially on shoulder and pin surfaces on weld formation are still lack of sufficient research. Tool fracture and process instability especially in thin sheet welding are two main problems in BT-FSW. Band pattern, Lazy S and void defects are three common phenomena that needs special attention in BT-FSW welds due to significant adverse effects on mechanical properties of joints. Although BT-FSW has some industrial applications especially in aerospace structures, its widespread use still needs to overcome various
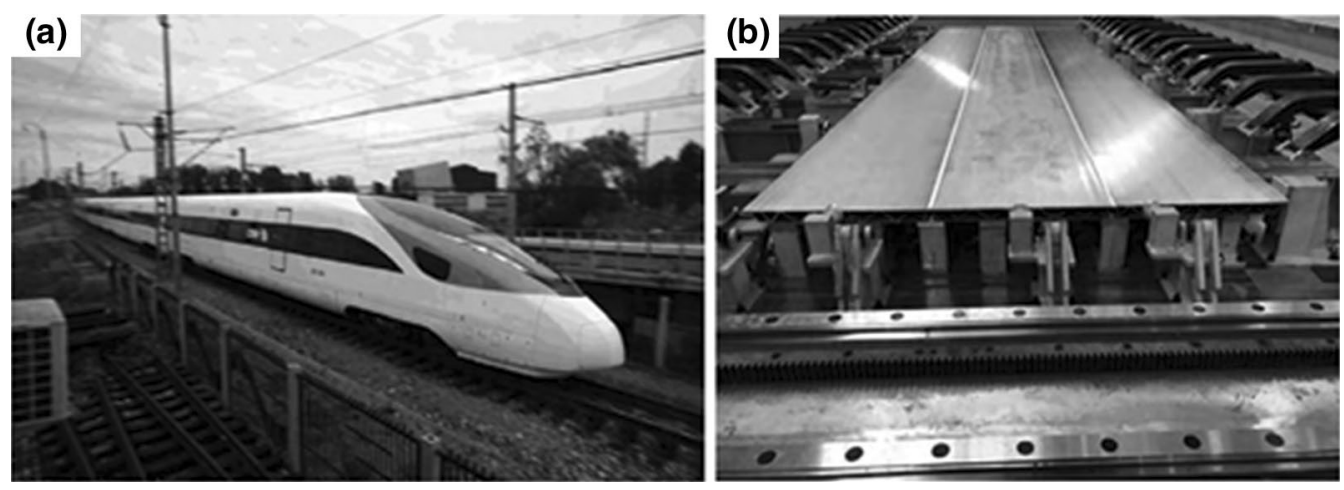

Fig. 23 a "Fuxing" high-speed train; $\mathbf{b}$ its flat roof produced using BT-FSW [70] 
constraints from tool lifetime, process stability, control complexity, implementation cost, etc.

According to the development status of BT-FSW, some possible research hotspots in the future are considered as follows:

(1) Optimize the shape, size and material selection of bobbin tools based on numerical simulation and a few trials to improve tool life, process stability and weld quality.

(2) Optimize control strategies of BT-FSW system to improve the process stability especially in thin sheet welding and develop robotic BT-FSW system to improve weld reliability and productivity.

(3) Study the effects of bobbin tool features especially on shoulder and pin surfaces on weld formation and then establish the relationship between tool features and weld formation.

(4) Reveal the underlying mechanism of weld and defects formation based on numerical simulation of temperature field and flow field, material tracking and weld microstructure, etc.

(5) Extend the application of BT-FSW to join similar and dissimilar materials.

\section{References}

[1] W.M. Thomas, E.D. Nicholas, J.C. Needham, M.G. Church, P. Templesmith, C. Dawes. Friction stir welding, GB Patent 9,125,978,9, Sept 1991

[2] R.S. Mishra, Z.Y. Ma, Mater. Sci. Eng. R 50, 1 (2010)

[3] G.Q. Wang, Y.H. Zhao, Y.F. Hao, J. Mater. Sci. Technol. 34, 73 (2018)

[4] R. Rai, A. De, H.K.D.H. Bhadeshia, T. DebRoy, Sci. Technol. Weld. Join. 16, 325 (2011)

[5] D. Wang, B.L. Xiao, D.R. Ni, Z.Y. Ma, Acta Metall. Sin. (Engl. Lett.) 27, 816 (2014)

[6] G.K. Padhy, C.S. Wu, S. Gao, J. Mater. Sci. Technol. 34, 1 (2018)

[7] X.Q. Liu, H.J. Liu, T.H. Wang, X.G. Wang, S. Yang, J. Mater. Sci. Technol. 34, 102 (2018)

[8] W.M. Thomas, C.S. Wiesner, D.J. Marks, D.G. Staines, Sci. Technol. Weld. Join. 14, 247 (2009)

[9] M. Skinner, R.L. Edwards, Mater. Sci. Forum 426-432, 2849 (2003)

[10] R. Edwards, G. Sylva, in Proceedings of the 7th International Conference on Trends in Welding Research, Pine Mountain, GA, U.S., 16-20 May (2005)

[11] L. Wan, Y.X. Huang, Z.L. Lv, S.X. Lv, J.C. Feng, Mater. Des. 55, $197(2014)$

[12] Y.X. Huang, L. Wan, S.X. Lv, J.C. Feng, Sci. Technol. Weld. Join. 18, 239 (2013)

[13] J. Hilgert, Dissertation, Hamburg University of Technology, 2012

[14] P.L. Threadgill, M.M.Z. Ahmed, J.P. Martin, J.G. Perrett, B.P. Wynne, Mater. Sci. Forum 638-642, 1179 (2010)

[15] F.F. Wang, W.Y. Li, J.J. Shen, S.Y. Hu, J.F. dos Santos, Mater. Des. 86, 933 (2015)

[16] S. Mohammad Kamil, Dissertation, University of Canterbury, 2015
[17] W.M. Thomas, M.J. Russell, A. Duncan, A. Robelou, in Proceedings of the 2nd International Aluminium Congress and Exposition. Queretaro, Mexico, 16-19 June (2010)

[18] F.F. Wang, Dissertation, Northwestern Polytechnical University, 2016

[19] M.K. Sued, D. Pons, J. Lavroff, E.H. Wong, Mater. Des. 54, 632 (2014)

[20] R. Carter, K. Lawless, J. NASA Tech. Briefs 32, 27 (2008)

[21] F.F. Wang, W.Y. Li, J.J. Shen, Q. Wen, J.F. dos Santos, J. Mater. Sci. Technol. 34, 135 (2018)

[22] A.C.J. Nunes, J. NASA Tech. Briefs 31, 21 (2007)

[23] S.B. Aziz, M.W. Dewan, D.J. Huggett, M.A. Wahab, A.M. Okeil, T.W. Liao, Acta Metall. Sin. (Engl. Lett.) 31, 1 (2018)

[24] X. Wei, Further development of the FSW floating-bobbin technique. https://www.twi-global.com. December 2011

[25] J. De Backer, Development and assessment of robotic bobbin and stationary shoulder friction stir welding. https://www.twi-globa 1.com. January 2018

[26] P.Y. Xia, Y.H. Yin, H.H. Zhao, X.M. Liu, X.S. Feng, L.J. Guo, Electr. Weld. Mach. 48, 294 (2018)

[27] S.A. Amin, A.F. Mohamed, Al-Khwarizmi Eng. J. 14, 1 (2018)

[28] M.K. Sued, D.J. Pons, Int. J. Man. Eng. 2016, 14 (2016)

[29] H.J. Liu, J.C. Hou, H. Guo, Mater. Des. 50, 872 (2013)

[30] H.J. Liu, J.C. Hou, Y.Q. Zhao, CN Patent, 101979209A, 2011

[31] J. Goebel, M. Reiman, A. Norman, J.F. dos Santos, J. Mater. Process. Technol. 245, 37 (2017)

[32] J.Y. Li, X.P. Zhou, C.L. Dong, J.H. Dong, J. Aeronaut. Mater. 33, $36(2013)$

[33] X.P. Zhou, Dissertation, Jiangsu University of Science and Technology, 2013

[34] B.H. Zhang, Dissertation, Shandong University, 2017

[35] J.H. Dong, C. Gao, Y. Lu, J. Han, X.D. Jiao, Z.X. Zhu, Int. J. Miner. Metall. Mater. 24, 171 (2017)

[36] X.M. Liu, J.S. Yao, Y. Cai, H. Meng, Z.D. Zou, Appl. Mech. Mater. 433, 2091 (2013)

[37] P. Singh, P. Biswas, S.D. Kore, J. Phy. Conf. Ser. 759, 1 (2016)

[38] K. Fraser, L. St-Georges, L.I. Kiss, in Proceedings of the 10th International Friction Stir Welding Symposium, Beijing, China, 20-22 May (2014)

[39] J. Hilgert, H. Schmidt, J.F. dos Santos, in Proceedings of the COMSOL Conference, Milan, 14-16 October (2009)

[40] J. Hilgert, H.N.B. Schmidt, J.F. dos Santos, N. Huber, J. Mater. Process. Technol. 211, 197 (2010)

[41] J. Hilgert, L.L. Huetsch, J.F. dos Santos, in Proceedings of the COMSOL Conference, Paris, 17-19 November (2010)

[42] J. Hilgert, J.F. dos Santos, N. Huber, Sci. Technol. Weld. Join. 17, 454 (2012)

[43] S.J. Chen, in Proceedings of the 1st International Joint Symposium on Joining and Welding, Osaka, Japan, 6-8 November 2013

[44] X.C. He, F. Gu, A. Ball, Progr. Mater. Sci. 65, 1 (2014)

[45] Y.H. Zhao, Y.M. Li, Y.F. Hao, Y.Y. Chen, G.Q. Wang, Aerosp. Mater. Technol. 42, 70 (2012)

[46] W.F. Xu, Y.X. Luo, W. Zhang, M.W. Fu, J. Mater. Sci. Technol. 34, 173 (2018)

[47] K.S. Arora, S. Pandey, M. Schaper, R. Kumar, J. Mater. Sci. Technol. 26, 747 (2010)

[48] J.J. Shen, F.F. Wang, U.F.H. Suhuddin, S.Y. Hu, W.Y. Li, J.F. Dos Santos, Metall. Mater. Trans. A 46, 2809 (2015)

[49] Q. Wen, W.Y. Li, Y.J. Gao, J. Yang, F.F. Wang, Int. J. Adv. Manuf. Technol. 100, 2679 (2019)

[50] L. Wan, Y.X. Huang, Z.L. Lv, S.X. Lv, J.C. Feng, Mater. Sci. Technol. 31, 1433 (2014)

[51] J.C. Hou, H.J. Liu, Y.Q. Zhao, Int. J. Adv. Manuf. Technol. 73, $1073(2014)$

[52] L. Zhou, G.H. Li, C.L. Liu, J. Wang, Y.X. Huang, J.C. Feng, F.X. Meng, Int. J. Adv. Manuf. Technol. 89, 3509 (2017) 
[53] H.J. Zhang, M. Wang, X. Zhang, G.X. Yang, Mater. Des. 65, 559 (2015)

[54] M. Esmaily, N. Mortazavi, W. Osikowicz, H. Hindsefelt, J.E. Svensson, M. Halvarsson, G.E. Thompson, L.G. Johansson, Corros. Sci. 111, 98 (2016)

[55] K. Warsinski, M. West, J. Freeman, T. Curtis, in Investigation of Lazy s Feature in Self-Reacting Tool Friction Stir Welds, ed. by M. Rajiv, M. Murray, S. Yutaka, H. Yuri, V. Ravi (Wiley, Hoboken (NJ), 2011), pp. 171-176

[56] J. Zhang, G. Li, C.Q. Li, G.H. Luan, Weld. Join. 11, 50 (2008)

[57] A.L. Lafly, D. Alléhaux, F. Marie, C. Dalle Donne, G. Biallas, Weld. World 50, 98 (2006)

[58] M. Esmaily, N. Mortazavi, W. Osikowicz, H. Hindsefelt, J.E. Svensson, M. Halvarsson, J. Martin, L.G. Johansson, Mater. Des. 108, 114 (2016)

[59] F. Marie, D. Alléhaux, B. Esmiller, in Proceedings of the 5th International Symposium on Friction Stir Welding, Metz, France, 14-16 September (2004)

[60] T. Neumann, R. Zettler, P. Vilaça, J. F. dos Santos, L. Quintino, Analysis of Self-ReactingFriction Stir Welds in a 2024-T351Alloy. in Friction Stir Welding and Processing IV, TMS, vol, 29 (2007), pp. 55-72
[61] T. Monica, Dissertation, The University of Texas, 2011

[62] H.J. Liu, J.C. Hou, H. Guo, Mater. Sci. Forum 706-709, 990 (2012)

[63] J.H. Dong, X.S. Nie, J.W. Yan, C.L. Dong, G.H. Luan, Trans. China Weld. Inst. 34, 85 (2013)

[64] H.J. Zhang, M. Wang, X. Zhang, J.B. Zhang, Trans. China Weld. Inst. 36, 65 (2015)

[65] D. Kinchen, External Tank Weld Technical Interchange (Lockheed Martin Manned Space Systems, New Orleans, Louisiana, 2009)

[66] P. McGill, J. Burkholder, in National Space and Missile Materials Symposium. Tampa, Florida, U.S., 25 June (2012)

[67] D. Kinchen, External Tank Friction Stir Weld Program Technical Presentation (Lockheed Martin Manned Space Systems, New Orleans, Louisiana, 2008)

[68] K.J. Colligan, A.K. O’Donnell, J.W. Shevock, M.T. Smitherman, in 9th International Symposium on Friction Stir Welding, Huntsville, AL, U.S., 15-17 May 2012

[69] A. Barbini, J. Carstensen, J.F. Dos Santos, J. Mater. Sci. Technol. 34, 128 (2018)

[70] J. Liu, G. Deng, F.W. Han, J.H. Yang, Weld. Join. 1, 17 (2015)

[71] E.C. Dalder, J.W. Pastrnak, J. Engel, R.S. Forrest, Weld. J. 87, 40 (2008) 